\title{
A Sustainable Natural Clam Shell Derived Photocatalyst for the Effective Adsorption and Photodegradation of Organic Dyes
}

Hailong Zhang ( $\nabla$ h_l_zhang@yahoo.com )

Zhejiang Ocean University

Xinxin Yao

Zhejiang Ocean University

Ting Qu

Zhejiang Ocean University

Gary Owens

University of South Australia

Liangjun Gao

Zhejiang Ocean University

Research Article

Keywords: Clam shell, Calcination, Congo red, Methylene blue, Photocatalysis

Posted Date: November 10th, 2021

DOI: https://doi.org/10.21203/rs.3.rs-1039754/v1

License: (c) (1) This work is licensed under a Creative Commons Attribution 4.0 International License.

Read Full License 

effective adsorption and photodegradation of organic dyes

3

4 Xinxin Yao a ${ }^{\text {, Ting }} \mathbf{Q u}{ }^{\text {b }}$, Gary Owens ${ }^{\mathrm{c}}$, Liangjun Gao ${ }^{\text {a }}$, Hailong Zhang a*

5

${ }^{\text {a }}$ Zhejiang Key Laboratory of Petrochemical Environmental Pollution Control, National-Local Joint Engineering

6 Laboratory of Harbor Oil and Gas Storage and Transportation Technology, School of Petrochemical

7 Engineering and Environment, Zhejiang Ocean University, Zhoushan, Zhejiang, 316022, China

8

${ }^{\mathrm{b}}$ National Engineering Research Center for Marine Aquaculture, Institute of Innovation \& Application, Zhejiang

9 Ocean University, Zhoushan, Zhejiang, 316022, China

${ }^{\mathrm{c}}$ Environmental Contaminants Group, Future Industries Institute, University of South Australia, Mawson Lakes Campus, Mawson Lakes, South Australia, 5095, Australia 
In response to the increasing desire for modern industries to be both green and sustainable, there has been increasing research focus on the reutilization of natural waste materials to effectively remove and degrade toxic wastewater effluents. One interesting food industry waste product is clam shells. Here a new photocatalytic nanomaterial derived from marine clam shells was successfully prepared and characterized. Thereafter the material was applied for the removal of two target dyes from aqueous solution, where the effect of both catalyst dose and initial dye concentration on adsorption and photocatalysis properties was investigated. The maximum adsorption capacities of methylene blue $(100 \mathrm{mg} / \mathrm{L})$ and Congo red (500 $\mathrm{mg} / \mathrm{L}$ ) were $123.45 \mathrm{mg} / \mathrm{g}$ and $679.91 \mathrm{mg} / \mathrm{g}$, respectively, where adsorption followed pseudo second order kinetics predominantly via a chemical adsorption process. The photodegradation removal efficiencies of the two dye solutions under visible light irradiation were $99.6 \%$ and $83.3 \%$ for MB and CR respectively. These results demonstrated that a clam shell catalyst also exhibited excellent degradation performance in a mixed dye solution with strong degradation capability and low cost, making the material a good candidate for practical field remediation of dye contaminated wastewater.

\section{Keywords:}

Clam shell; Calcination; Congo red; Methylene blue; Photocatalysis 


\section{Introduction}

While water is essential for all life, the rapid growth in modern human civilizations globally, concurrent with vigorous and rapid industrialization has resulted in significant pollution of water resources through the discharge of waste materials, especially by the dye industry. Water resource contamination by dye wastewaters is becoming increasingly serious (Chequer et al., 2009). Methylene blue (MB), Congo red (CR) and many other organic dyes are widely and routinely used in large quantities by various dye industries. These dye molecules have a complex molecular structure containing many diverse functional groups such as amino, hydroxyl and the benzene ring (Balakrishnan et al., 2016), which while giving the dye strong coloring ability also result in strong toxicity and poor biodegradability (Chen et al., 2018). These latter features are of concern because the efflux of large concentrations of dyes into the natural environment may thus lead to environmental harm. Hence, development of new materials to treat dye wastewater is urgently required to mitigate environmental pollution. While many non-destructive methods, such as adsorption, membrane filtration, and precipitation, have previously been successfully employed to remove dye from wastewater, the disadvantage of nondestructive methods are that do they nor destroy the dye but merely concentrate the dye into either sludge or silt, which still needs further treatment to remove the hazard (Tsai et al., 2020). In comparison, destructive methods, can directly decompose large dyes into non-toxic smaller molecules, can be directly discharged into the environment. Therefore, of the destructive methods, photocatalytic reduction has emerged as a popular destructive method. For example, bismuth oxychloride nanomaterials were synthesised via a hydrothermal method, and used for the degradation rate of Congo red with a $72 \%$ photocatalytic removal efficiency (Ismail et al., 2019). $\mathrm{A} \mathrm{Fe}_{2} \mathrm{O}_{3}-\mathrm{CeO}_{2}$ nanocomposite prepared by a precipitation and improved sol gel self-ignition method, exhibited a $96 \%$ photodegradation removal efficiency for CR (Aboutaleb et al., 2019). Ma et al (2017) also successfully synthesized a MgZnCr$\mathrm{TiO}_{2}$ nanocomposite photocatalyst by co-precipitation, which removed $99.8 \%$ of CR 
after $180 \mathrm{~min}$. However, the disadvantage of these artificially synthesized catalysts was that the preparation process was complex and, also required expensive and toxic chemical reagents. The application of nanomaterials for photocatalysis is highly desirable due the nanomaterial's high surface areas and semiconductor heterogeneous structures, which significantly improves dye degradation efficiency. Although many nanoparticles have been reported for effective degradation, there are only a few studies which have considered the preparation of photocatalysts from waste materials. Shariffuddin et al (2018) investigated the feasibility of using $\mathrm{CaO}$ derived from cockle shells as catalyst for MB removal and demonstrated good degradation. Likewise, E$\mathrm{CaO}$ nanoparticles derived from waste eggshell were successfully prepared by calcination method for efficient photodegradation of methylene blue (MB) and toluidine blue (TB) (Sree et al., 2020), where preparation of E-CaO was both ecofriendly and sustainable. These two studies clearly indicated that recycling wastes as nanomaterial remediating agents was certainly feasible. Hence, it is expected, that in the ongoing search for more efficient and sustainable degradation of dyes, natural photocatalysts derived from waste biomass waste will provide an economical, sustainable and environmentally friendly method.

Clams are widely distributed in both the North and South Seas of China, where they grow rapidly, with a short breeding cycle and exhibit strong adaptability, thus making them an excellent shellfish suitable for artificial high-density cultivation. Clam shell is a significant by-product of aquaculture, where not being fully utilized beneficially, results in large numbers of discarded clam shells being accumulated. These discarded clam shells contain remnants of meat and other organic residuals, which will rot potentially producing toxins after long-term exposure to the environment, which has negative impact on aquaculture, and also causes serious environmental pollution. Therefore, mishandling of by-products from aquaculture has 
previously led to environmental crisis due to the unwanted release of hazardous substances (Penarodriguez et al., 2010). Thus, an urgent waste issue to be resolved is how effectively and beneficially utilize waste clam shells. Previously oyster shells have been used to effectively adsorb $\mathrm{H}_{2} \mathrm{~S}$ from wastewater, with a maximum adsorption capacity of $12 \mathrm{mg} \mathrm{g}^{-1}$ (Asaoka et al., 2009). Through calcination and hydration, waste oyster shell has also been pretreated to increase its specific surface area and pore volume, for the removal of $\mathrm{SO}_{2} / \mathrm{NO}_{\mathrm{x}}$ (Jung et al., 2007). Oyster shell has also been used as an adsorption and filtration medium for phosphorus removal, where its use decreased eutrophication in wastewater (Park et al., 2008). have used Calcined mussel shells have been used to remove mercury ( $\mathrm{Hg}$ ) from water with good efficiency, reaching 90\% in 55 min (Penarodriguez et al., 2010). A mixture of mussel shell calcined ash, sewage sludge and wood ash were used successfully as an adsorbent for several metal ions, with removal efficiencies for $\mathrm{Hg}$, arsenic (As) and chromium (Cr) of is 98-99, 90-96, and 32\%, respectively (Secoreigosa et al., 2014). Many different natural materials have also been used to specifically remove anthropogenic dyes. The residual biomass of Spirulina platensis removed up to $82.6 \%$ of CR (Nautiyal et al., 2016), while carbonized kelp biochar performed even better, removing up to $94 \%$ of MB (Zhou et al., 2018). These reports indicate that waste utilization of marine aquaculture by-products has been an important issue. Even today, increasing attention has been directed towards better methods for the utilization of marine aquaculture by-products, as many studies have stressed the importance and necessity of global waste utilization. Thus, there seems to be great potential for the 
utilization of clam shell for cost-effective environmental pollution control. However, to the best of our knowledge, the potential for clam shell to act as a natural photocatalyst for dye degradation has not been previously studied, but this seems likely given the previous successes outlined above.

Thus, in this work, a natural photocatalyst based on calcium oxide derived from clam shell was synthesised via a high temperature calcination method and its physiochemical properties fully characterized by SEM, TEM, BET, XRD, XPS, UVvis and TGA. Thereafter, the as-prepared photocatalysts were evaluated for their ability to adsorb and photocatalytically degrade both cationic (MB) and anionic (CR) dyes, where the mechanism of adsorption and photocatalytic degradation was explored.

\section{Materials and Methods}

\subsection{Materials}

Clam shells were collected from a local market in Zhoushan, Zhejiang Province.

Methylene blue (MB), Congo red (CR), sodium hydroxide, hydrochloric acid, pbenzoquinone, isopropanol, hydrogen peroxide and ammonium oxalate were all purchased from Shanghai Guoyao Chemical Reagent Co., Ltd. All chemicals used in this work were analytical grade and were used directly as received without further purification.

\subsection{Preparation of clam shell catalyst}

Clam shells were initially washed with tap water to remove any obvious 
contamination from the surface of the clam shell. Thereafter, clam shells were immersed in a solution of $1 \mathrm{M}$ sodium hydroxide and heated to $85^{\circ} \mathrm{C}$ in a water bath remove any residual meat from the surface of the clam shells, then, the samples were rinsed with fresh water $(\mathrm{pH}=7)$, and evaporated until dryness at $80^{\circ} \mathrm{C}$ on a stove. The clam shells were soaked in $1 \mathrm{M}$ hydrochloric acid solution in a clam pot overnight, washed with deionized water several times and dried. Finally, the clam shell was calcined in a muffle furnace for $2 \mathrm{~h}$ at 800,900 , and $1000{ }^{\circ} \mathrm{C}$ respectively. After calcination, the white powder obtained was ground, sieved (100 mesh) and stored in a desiccator for later use.

\subsection{Characterization}

Specific surface area and pore size distribution of samples, was calculated using the BET method from $\mathrm{N}_{2}$ adsorption/desorption isotherms obtained using a static volumetric adsorption analyzer (Micromeritics ASAP 2010, Shanghai, China).

Morphology and microstructure of the as-prepared samples was determined via a scanning electron microscope (SEM; S4800, Hitachi, Japan) and high-resolution transmission electron microscope (HR-TEM; Joel-2100, JEOL, Japan). Crystal structures were analyzed by X-ray diffraction (XRD, RIGAKU miniflex/600, Japan) in the range between $20^{\circ}-80^{\circ}$. Thermogravimetric analysis was conducted on a TGA Q5000 (American TA instrument Q Series) to better understand phase transformations during calcination. Optical properties of samples, were examined using a Cary 500 UV-vis NIR spectrophotometer in the range $200-800 \mathrm{~nm}$. The chemical states of elements at the near surface of samples were also studied using X- 
ray photoelectron spectroscopy (XPS, Phi 5000C ESCA system, USA).

\subsection{Photocatalytic experiment}

As-prepared photocatalyst $(20 \mathrm{mg})$ was added into an aqueous solution of either $\mathrm{MB}$ or $\mathrm{CR}(40 \mathrm{~mL})$ and the solution was magnetically stirred in the dark. for 2 hours for the reaction to achieve adsorption equilibrium. During this time aliquots of the supernatant solution were removed at regular intervals (i.e., $0,5,10,20,30,60,90$ and $120 \mathrm{~min}$ ) an analyzed for the residual dye concentration. To assess adsorption performance, residual dye concentration were determined photometrically.

After $2 \mathrm{~h}$ dark reaction, a light source (xenon lamp, HSX-F300) was used to initiate photocatalytic experiments. The vertical distance between the light source and the reactor was $10 \mathrm{~cm}$, and supernatant samples were again taken at regularly intervals to assess photocatalytic performance. In the photocatalytic system, a cooling reflux device was also connected to the reaction vessel to eliminate the influence of heat generated by light on the experiment.

The effects of different dye concentrations (MB: 50, 75, and 100 ppm; CR: 400, 450 , and $500 \mathrm{ppm})$, and different catalyst doses $(20,40,60$, and $80 \mathrm{mg})$ were also explored.

\subsection{Determination of dye concentration}

After the reaction single dye solution samples were initially centrifuged at $4000 \mathrm{r}$ $\min ^{-1}$ for $10 \mathrm{~min}$, and the absorbance of the supernatant subsequently measured using an UV-vis spectrophotometer. The wavelengths of absorbance maxima for the two 
dyes were $\lambda_{\mathrm{MB}}: 664$, and $\lambda_{\mathrm{CR}}: 497 \mathrm{~nm}$. The removal efficiency (R\%) of adsorbed dye was calculated by Eq (1), where the amount of dye adsorbed on the catalyst $\mathrm{q}_{\mathrm{e}}(\mathrm{mg} / \mathrm{g})$ was calculated by Eq (2).

$$
\begin{gathered}
R(\%)=\frac{c_{0}-c_{e}}{c_{0}} \times 100 \% \\
q_{e}=\frac{\left(C_{0}-C_{e}\right) V}{m} \\
-\ln \left(\frac{C_{t}}{C_{0}^{\prime}}\right)=k t
\end{gathered}
$$

where $\mathrm{C}_{0}$ and $\mathrm{C}_{\mathrm{e}}\left(\mathrm{mg} \mathrm{L}^{-1}\right)$ were respectively, the initial and equilibrium dye concentrations in solution, $\mathrm{m}(\mathrm{g})$ was the mass of cataclysm and $\mathrm{V}(\mathrm{L})$ was the volume of dye solution. In order to study reaction kinetics, the rate constant $\mathrm{k}$ was obtained by curve fitting data to $\mathrm{Eq}(3) \mathrm{t}$, where $\mathrm{C}_{0}{ }_{0}$ is the initial dye concentration after dark reaction and $\mathrm{C}_{\mathrm{t}}$ is the dye concentration at light irradiation time $\mathrm{t}$.

\subsection{Adsorption kinetics under dark reaction}

Adsorption kinetics of the single dye system was further studied by adding catalyst to the dye solution under dark conditions with constant magnetic stirring and measuring the residual dye concentration in the solution at fixed time periods. The kinetic data so obtained was fit to both pseudo first order (PFO Eq 4) and second order (PSO Eq 5) kinetics to evaluate the kinetics of adsorption.

$$
\begin{gathered}
\ln \left(q_{e}-q_{t}\right)=\ln q_{e}-k_{1} t \\
\frac{t}{q_{t}}=\frac{1}{k_{2} q_{e}{ }^{2}}+\frac{t}{q_{e}}
\end{gathered}
$$


where $\mathrm{q}_{\mathrm{t}}\left(\mathrm{mg} \mathrm{g}^{-1}\right)$ is the dye adsorption capacity at time $(\mathrm{t})$; and $\mathrm{k}_{1}\left(\min ^{-1}\right)$ and $\mathrm{k}_{2}(\mathrm{~g}$ $\mathrm{mg}^{-1} \mathrm{~min}^{-1}$ ) are the rate constants for PFO and PSO models, respectively.

\section{Results and discussion}

\subsection{Characterization of catalyst}

\subsubsection{Morphology}

The changes in clam shell powder morphology following calcination at three different temperatures were monitored using SEM and TEM (Fig. 1). Before calcination, clam shell powder had a spongy porous structure (Fig. a,b), due to presence of organic matter and a calcium carbonate skeleton after soaking in acid. However, after calcination at $800{ }^{\circ} \mathrm{C}$, the clam shell surface became fragmented and bulky, due to the consumption of organic matter and growth of crystal particles (Fig. 1c,d). As calcination temperature further increased $\left(900\right.$ and $\left.1000^{\circ} \mathrm{C}\right)$, clam shell powder morphology and surface structure became more compact. The increase in particle size was attributed particle sintering, resulting in Ostwald ripening, which causes growth of larger particles at the expense of smaller ones. This was consistent with previous results which had shown an increase in average surface grain size with calcination temperature (Peralta et al., 2017).

More detailed morphological characteristics of clam shell calcined at $1000{ }^{\circ} \mathrm{C}$ were obtained by HR-TEM (Fig. 1 i-k), and showed that after high temperature calcination the clam shell catalyst (CSC) had a layered structure where the distance between two adjacent lattices at the interface was $0.286 \mathrm{~nm}$, which was consistent with XRD results (section 3.1.3) corresponding to the $\mathrm{CaO}$ (111) crystal face. In 
addition, the observed heterojunctions between dislocations in the crystal structure may be due to the rearrangement of additional atomic layers produced by the presence of trace metals in the CSC during calcination (Wei et al., 2018). This may enable greater electron migration to the conductive band of $\mathrm{CaO}$, since the energy band gap is reduced and charge carrier separation is increased, therefore improving photocatalytic performance.

\subsubsection{BET analysis}

$<$ Insert Fig. 1 here $>$

All samples exhibited Type IV isotherms (Fig. S1 a and b) with hysteresis loops. The presence of small hysteresis loops at $\mathrm{P} / \mathrm{P}_{0}>0.4$ indicated the existence of both microporous and mesoporous structures (Yao et al., 2020). After calcination, specific surface area, pore volume and average pore diameter of the catalyst all decreased (Table S1). This was because as a result of an increase in calcination temperature, the inner part of the particles shrunk more, leading to an overall decrease in the pore size of the material. However, specific surface area of the catalyst did increase slightly between 800 and $1000^{\circ} \mathrm{C}$, which was attributed to the formation of micro pores following decomposition of calcium carbonate. Adherence to the Type IV isotherm model clearly indicated the formation of multilayers on the catalyst surface during high temperature reactions, which was also clearly observed in TEM imagery (Fig 1 i).

\subsubsection{X-ray diffraction analysis}


showed that the main component of untreated clam shell was $\mathrm{CaCO}_{3}$, where

diffraction peaks at $2 \theta=26.21^{\circ}, 27.21^{\circ}, 45.85^{\circ}$ and $50.22^{\circ}$ correspond to calcium

carbonate on (111), (021), (221) and (132) crystal faces, respectively (PDF 70-1849).

However, the XRD pattern of samples calcined at $800{ }^{\circ} \mathrm{C}$ for $2 \mathrm{~h}$ did not match well

carbonate, the main component of the clam shell, would have experienced major

However, $800^{\circ} \mathrm{C}$ is not enough for complete conversion, so the calcined material

contains a large portion of intermediate phase/material between calcium carbonate and calcium oxide. For samples calcined for $2 \mathrm{~h}$ at either 900 or $1000{ }^{\circ} \mathrm{C}$ the diffraction peaks at $32.20^{\circ}, 37.35^{\circ}, 53.85^{\circ}, 64.15^{\circ}$ and $67.37^{\circ}$ corresponded to calcium oxide on

280 (111), (200), (220), (311) and (222) crystallographic planes, respectively (Jiang et al., 2018). In addition, closer comparison of the XRD patterns of the samples calcined at $900{ }^{\circ} \mathrm{C}$ and $1000{ }^{\circ} \mathrm{C}$, showed that several small peaks present at $900{ }^{\circ} \mathrm{C}$ disappeared at $1000{ }^{\circ} \mathrm{C}$. This was attributed to either further mass loss of trace metals or the complete conversion of intermediate substance to $\mathrm{CaO}$. During calcination, calcium carbonate, the main component of clam shell, undergoes an initial phase change from aragonite to calcite, and then subsequently from calcite to $\mathrm{CaO}$.

$$
<\text { Insert Fig. } 2 \text { here }>
$$

\subsubsection{Thermogravimetric analysis}

Thermogravimetric analysis provides further information on the transformation 
290

291

292

293

294

295

296

297

298

299

300

301

302

303

304

305

306

307

308

309

310

311

of clam shell powder during calcination. The initial mass lost from clam shell was only $0.47 \%$ due to the loss of water between $30-200{ }^{\circ} \mathrm{C}$ (Fig. 2b). Thereafter, the curve decreased slightly between $200-500{ }^{\circ} \mathrm{C}$, due to the decomposition and removal of organic components of the clam shell, whereas weight loss between $500-610{ }^{\circ} \mathrm{C}$ was attributed to a phase transformation from aragonite to calcite. Thereafter, the mass of clam shell decreased significantly between 610 and $800^{\circ} \mathrm{C}$, due to further conversion of calcite to $\mathrm{CaO}$ and $\mathrm{CO}_{2}$, during calcination (Shariffuddin et al., 2018).

At $800-900{ }^{\circ} \mathrm{C}$, further mass loss was caused by removal of any residual intermediate products from incomplete conversion of $\mathrm{CaCO}_{3}$ to $\mathrm{CaO}$, and thereafter the slight decrease observed at $900-1000{ }^{\circ} \mathrm{C}$, may be due to the presence of a small amount of unconverted $\mathrm{CaCO}_{3}$ and further mass loss of trace metals. All these results were in good agreement with both XRD (Section 3.1.3) and XPS (Section 3.1.6) analysis.

\subsubsection{Ultraviolet visible spectrum analysis}

Diffuse reflectance spectroscopy in the UV-vis range was employed to investigate the optical properties of uncalcined clam shell powder and clam shell calcined at three different temperatures (Fig. 2c), as well as the light absorption characteristics and band gap energy of the CSCs (Fig. 2d). The wavelength absorption maxima of uncalcinated, 800,900 and $1000{ }^{\circ} \mathrm{C}$ samples were $277,271,276$ and 273 $\mathrm{nm}$, respectively (Fig. 2c), corresponding to the optical band gap obtained from Tauc diagram (Fig. 2d). It was found that the optical band gap of the catalysts decreased 
with an increase in calcination temperature, and thus the lowest band gap $(2.64 \mathrm{eV})$ was obtained at $1000{ }^{\circ} \mathrm{C}$. As the calcination temperature increased, the weight of clam shell decreased, and the specific gravity of trace metal elements increased. Therefore, the decrease in optical band gap with increased calcination temperature was attributed to the appearance of localised energy states in the $\mathrm{CaO}$ band gap and the existence of a higher content of lattice defects, i.e., increases in trace metals and oxygen vacancies (Shajahan et al., 2020). High resolution TEM (Section 3.1.1) had also confirmed the existence of a large number of lattice defects.

\subsubsection{XPS analysis}

In order to analyze the valence state and content of surface elements in clam shell powder before and after high temperature $\left(1000^{\circ} \mathrm{C}\right)$ calcination, XPS was performed and compared on clam shell treated at 800 and $1000{ }^{\circ} \mathrm{C}$ (Fig, 3). Survey scans (Fig. 3a), indicated that the main components of clam shells at 800 and $1000{ }^{\circ} \mathrm{C}$ were $\mathrm{C}, \mathrm{O}, \mathrm{Ca}$ and a small amount of $\mathrm{Na}$. It is likely that traces of other metals such as magnesium $(\mathrm{Mg})$ are also present but these would be at levels below the detection limit of XPS (i.e., $<0.01 \%$ ).

For clam shell powder calcined at $800{ }^{\circ} \mathrm{C}$, the XPS spectra (Fig. 3b) exhibited many superimposed C1s peaks (C1-C3), where $\mathrm{C} 1$ with a binding energy of $285 \mathrm{eV}$, was attributed to amorphous carbon/adventitious carbon, a small standard C2 peak at $286.1 \mathrm{eV}$, corresponded to the $\mathrm{C}-\mathrm{O}$, and the $\mathrm{C} 3$ peak at $289.4 \mathrm{eV}$ corresponded to a binding energy commonly associated with metal carbonate $\mathrm{MCO}_{3}$, and was thus 
attributed to $\mathrm{CaCO}_{3}$. In comparison, for clam shell calcined at $1000{ }^{\circ} \mathrm{C}$ (Fig. 3e), the binding energy of the adventitious carbon peak $\mathrm{C} 1$ occurred at $285 \mathrm{eV}$, the $\mathrm{C} 2$ peak for organic carbon (C-O bond) occurred at $286 \mathrm{eV}$, the $\mathrm{C} 3$ peak attributable to $\mathrm{COOR}$ at $288 \mathrm{eV}$, and the $\mathrm{C} 4$ peak corresponding to $\mathrm{MCO}_{3}$ at $289.4 \mathrm{eV}$. However, compared with the sample calcined at $800^{\circ} \mathrm{C}$, the sample calcined at $1000^{\circ} \mathrm{C}$, exhibited two extra weak peaks (C5 and C6) at 292 and $295 \mathrm{eV}$, respectively, which were attributed to compounds formed by carbon and/or halogen. The observed peak (O1) at $530.8 \mathrm{eV}$ for the $800{ }^{\circ} \mathrm{C}$ calcined sample in the O1s XPS spectra was attributed to $\mathrm{CO}_{3}{ }^{2-}$ of $\mathrm{CaCO}_{3}$ (Fig. 3c); whereas the binding energy of the peak at $531.6 \mathrm{eV}$ (peak O2) for the clam shell calcined at $1000^{\circ} \mathrm{C}$ (Fig. 3f). corresponded to $\mathrm{CaO}$.

Calcium typically exhibits two characteristic binding energies, i.e., Ca2p $\mathrm{p}_{3 / 2}(346$ $\mathrm{eV})$ and $\mathrm{Ca} 2 \mathrm{p}_{1 / 2}(349.6 \mathrm{eV})$ (Tangboriboon et al., 2012). Here high-energy resolution spectra of Ca2p peaks showed a complex pattern that could be deconvoluted into three (Ca1, CA2 and Ca3) constituent peaks (Fig. $3 \mathrm{~d}$ and g). For sample calcined at $800{ }^{\circ} \mathrm{C}$, peak $\mathrm{Ca} 1(346 \mathrm{eV})$, corresponding to $\mathrm{CaCO}_{3}$ and peak $\mathrm{Ca} 2(347.1 \mathrm{eV})$ was associated with $\mathrm{CaO}$. In comparison, for the $1000{ }^{\circ} \mathrm{C}$ calcined sample the area of the $\mathrm{CaO}$ peak (Ca2) increased, indicating that the content of $\mathrm{CaO}$ was relatively more when the sample was pyrolyzed at the higher temperature.

$<$ Insert Fig. 3 here $>$

\subsection{Adsorption-photodegradation performance}

\subsubsection{Effect of different catalysts}


357 for calcined clam shells at $1000{ }^{\circ} \mathrm{C}$ reached 99.7 and $90.8 \%$, respectively, under dark

358 conditions, the adsorption only removal efficiencies of MB and CR reached only 25.9

359 and $70.5 \%$, respectively (Fig. 4). In comparison the total absorption-photodegradation

360 removal efficiency of untreated clam shells (MB: $15.9 \%$, CR: $10.4 \%$ ), and those

361

calcined at $800{ }^{\circ} \mathrm{C}$ (MB: $53.9 \%$, CR: $25.9 \%$ ), or $900{ }^{\circ} \mathrm{C}$, (MB: $85.7 \%$, CR: $81.1 \%$ )

was lower. This indicated that the adsorption and/or photocatalytic properties of uncalcined clam shell or clam shell calcined at temperatures $<1000{ }^{\circ} \mathrm{C}$ were poorer than clam shell calcined at $1000^{\circ} \mathrm{C}$. It can also be clearly seen (Fig. 4) that the adsorption performance (dark environment) of clam shell calcined at different temperatures was consistently better than that of non-calcined clam shell. This suggested that decomposition of residual organic matter in the original clam shell via heat treatment during calcination, results in significantly more pore structure. Where the increase in adsorption performance with calcination temperature, could be attributed to increased pore forming effects from $\mathrm{CO}_{2}$ generated by thermal decomposition of $\mathrm{CaCO}_{3}$, the main component of clam shell. The photocatalytic activity (under light) of the clam shell powder was also enhanced by an increased calcination temperature. This may be due to an increase in the relative content of calcium oxide due to heating and the interaction of trace transition metals in the clam shell. HR-TEM images confirmed the presences of a significant number of dislocations and defects in the $\mathrm{CaO}$ crystal structure. Overall, the results from the adsorption-photodegradation study indicated that the best photocatalytic performance 
was obtained when clam shell powder was calcined at $1000^{\circ} \mathrm{C}$. This was attributed to synergetic effects of enhanced absorption and increased heterojunctions among some dislocations in the crystal structures, which also improved photodegradation efficiency.

Photodegradation kinetics of both MB and CR by CSCs varied with the calcination temperature of the catalyst (Fig. $4 \mathrm{~b}$ and d). The kinetic data for the degradation of both MB and CR best fit the pseudo first order kinetic model $\left(\mathrm{R}^{2}\right.$ approaching 1), where the rate constant $(\mathrm{k})$ increased with calcination temperature (Table 1), and the higher the $\mathrm{k}$ value, the better the photocatalytic performance and the greater the photodegradation amount. Thus, in all subsequent experiments, only clam shell calcined at $1000{ }^{\circ} \mathrm{C}$ were investigated.

The photodegradation of both MB and CR by $1000{ }^{\circ} \mathrm{C}$ calcined CSC occurs in the visible light region of the absorption spectrum (Fig. 4e and f). As reaction time increased, peaks of MB and CR both decreased sharply, and some peaks disappeared or were slightly shifted in wavelength, which indicated that both MB and CR molecules were being destroyed, and that new substances (degradation products) were also formed (Shariffuddin et al., 2018).

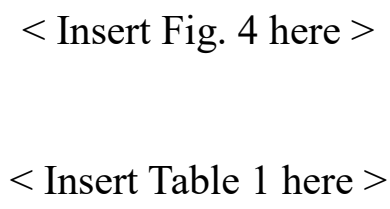

\subsubsection{Adsorption performances}

The adsorption performance of $1000^{\circ} \mathrm{C}$ calcined clam shell powder varied with 
the initial concentrations of MB and CR within 2 h. (Fig. S2) Over $2 \mathrm{~h}$ the concentration of both MB or CR decreased gradually after exposure to the CSC until the adsorption equilibrium was reached. When the initial dye concentration was low, equilibrium was reached relatively quickly, within $30 \mathrm{~min}$ ). For example, for $\mathrm{MB}$ a sharp decrease in MB concentration was observed in the first 10 min followed by a slower adsorption until the MB concentration stabilized. This is because when the initial dye concentration is low, the adsorption reaction can quickly reach equilibrium because there are a large number of sites available on the surface of CSC for adsorption relative to the number of $\mathrm{MB}$ molecules. As the initial concentration of dye increases, a more competitive adsorption for MB molecules for surface sites is induced. Thus, as more active sites become occupied, it becomes increasingly more difficult to adsorb dye due to a weaker attraction between the surface of CSC and the MB molecules, which leads to slowing of dye adsorption rate in the latter stages of the reaction.

In order to further investigate the adsorption mechanism of the MB dye on to the CSC, both pseudo first order (PFO) (Eq 4) and pseudo second order (PSO) (Eq 5) kinetic models were used for data analysis. The kinetic data for MB adsorption on to CSC fit both the PFO (Fig S2(c)) and PSO (Fig. S2(d)) models well with good linear behavior. However, the goodness of fit $\left(\mathrm{R}^{2}\right)$ for the PSO model was slightly higher than that for the PFO model, and the adsorption capacity at equilibrium obtained from PSO fitting was also closer to the experimental value (Table S2). The corresponding adsorption capacities for initial MB concentrations of 50, 75 and 100 ppm were 
422

423

experimentally is $60.52,96.72$ and $123.45 \mathrm{mg} \mathrm{g}^{-1}$, respectively. Therefore, the PSO model was more suitable for describing the adsorption system operating for the CSC. Based on the underlying assumptions of the PSO equation model this indicates that MB participated in chemical adsorption, involving the sharing or exchange of electrons between the hydrophilic edge sites of the CSC and the dye cations (Hosseinzadeh et al., 2015). As the initial MB concentration increased, the goodness of fit of adsorption capacity $\left(\mathrm{q}_{\mathrm{e}}\right)$ also increased, and became very close to the experimentally derived $\mathrm{q}_{\mathrm{e}}$ value, but the adsorption rate $\left(\mathrm{k}_{2}\right.$ value) decreased. This decrease in rate constant is due to the intense adsorption competition between relatively limited surface-active sites and a large number of MB molecules in a higher concentration dye solution, resulting in a relatively low-rate constant (Liu et al., 2014).

Similarly, the initial adsorption capacities of CR at 400, 455 and 500 ppm were $592.76,653.26$ and $679.91 \mathrm{mg} \mathrm{g}^{-1}$, respectively and fitting of the kinetic data to the same two models (Fig. S2 (g) and (h)) showed that the PSO model better described the adsorption system of CR on the CSC, and calculated adsorption amount at equilibrium was also closer to the experimental value (Table S2). As for MB, since the PSO model assumes chemical adsorption as the dominant adsorption process (Ardejani et al., 2008; Parvin et al., 2019), which involves the sharing or exchange of electrons between the hydrophilic edge sites of the CSC and the dye ions, this result also suggests that negatively charged CR ions were removed from solution via a chemical adsorption process. This adsorption may be caused by a combination of $\pi-\pi$ 
stacking, hydrogen bonding, and van der Waals forces. In addition, the $\mathrm{k}_{1}$ values for CR were much lower than those calculated for MB, which indicated that the CSC had a higher affinity for the negatively charged dye (Dai et al., 2018).

\subsubsection{Effect of catalyst dose}

The dose of catalyst is an important practical consideration and also plays an important role in the efficiency of photocatalytic reaction. An increase in catalyst dose will increase the overall concentration of active substance and hence increase the number of active sites in the reaction system. Thus, the probability of contact of dye molecules with the active sites increases, as does the reaction probability, and rate of reaction, leading to improved dye removal efficiency. For photodegradation removal processes there will generally be an increase in removal efficiency with increased dose until at a certain concentration the increase in catalyst amount reduces the light transmittance of the suspension (Nguyen et al., 2018) and hence the removal efficiency.

For MB and CR (Fig. 5) as the amount of CSC increased from 20, 40, 60 to 80 $\mathrm{mg}$, the removal efficiencies of $\mathrm{MB}$ were $99.7,99.8,99.9$ and $99.9 \%$, respectively, and $83.3,88.6,96.7 \%$ and $97.0 \%$ for CR, respectively. Thus, for both dyes' removal efficiency increases with catalyst dose, being almost a negligible for MB and only modest for CR. This indicated that even the lowest dose used here had an adsorption capacity well above the amount of dye in solution. Even though the increase in MB removal efficiency with dose was not very significant, the time required to achieve this removal became less as dose increased (Fig. 5b). Since even a $20 \mathrm{mg}$ catalyst 
dose could achieve a strong catalytic effect, in $40 \mathrm{~mL}$ dye solutions a catalyst dose of $0.5 \mathrm{~g} \mathrm{~L}^{-1}$ was selected for all subsequent experiments. According to the experimental data, enough binding sites can be reached at $20 \mathrm{mg}$. Although the removal efficiency further increases with the increase of the amount of catalyst, it will cause the waste of catalyst, that is, some more binding sites are not used.

$<$ Insert Fig. 5 here $>$ $<$ Insert Table 2 here $>$

The best fit kinetic parameters (Table 2) for MB and CR degradation under different catalyst doses showed that the degradation of both MB and CR followed pseudo first order kinetics, with good correlation ( $\mathrm{R}^{2}$ close to 1$)$.

The $\mathrm{k}$ value for MB increased slightly in the range of 20 - $40 \mathrm{mg}$, and decreased between 40 and $80 \mathrm{mg}$. This was potentially because the increase of catalyst above 40 mg reduced the light transmittance of the suspension, making it more difficult for photons to reach the CSC surface, and the amount of $\bullet \mathrm{OH}$ free radical formed between dye molecules and catalyst surface became relatively small. However, for $\mathrm{CR}$, the $\mathrm{k}$ value increased significantly between 20 and $60 \mathrm{mg}$, and slightly increased from 60 to $80 \mathrm{mg}$.

\subsubsection{Effect of initial dye concentration}

The removal efficiencies of MB dye at initial dye concentration of 50, 75 and 100 ppm were $99.8 \%, 99.7 \%$ and $99.6 \%$, respectively (Fig. 6). Although the removal efficiency did not significantly change with initial dye concentration, the time required for the photodegradation become longer (Fig. 6). Likewise, after 120 min of 
488

489

490

491

492

493

494

495

496

497

498

499

500

501

502

503

504

505

506

507

508

illumination, the overall removal efficiency of CR dye decreased with an increase in the initial dye concentration, being $98.2,90.8$ and $83.3 \%$, for CR concentration of 400, 450 and 500 ppm respectively. This is because the number of $\bullet \mathrm{OH}$ radicals formed on the catalyst surface and the number of interactions with dye molecules determine the overall efficiency of photocatalytic degradation. With an increase in the number of dye molecules in solution, the number of dye molecules contacting the catalyst surface also increase, causing active sites on the catalyst surface covered by them, these will affect the arrival of photons on the surface of the catalyst, which will reduce the catalytic efficiency, resulting in less $\bullet \mathrm{OH}$ radical generation on the catalyst surface. Therefore, increased dye concentration can lead to a reduction in both degradation efficiency and reaction rate (Zhu et al., 2000).

The variation in best fit degradation kinetic parameters for both MB and CR with different concentrations are shown in Table 3. The $\mathrm{k}$ values of both $\mathrm{MB}$ and CR increased as the initial dye concentration decreased. The maximum $\mathrm{k}$ value of 0.058 $\min ^{-1}$ was observed for MB, which demonstrated that this catalyst had the highest photocatalytic degradation rate for MB. This was also much higher than result obtained using other semiconductors such as $\mathrm{TiO}_{2} / \mathrm{MoS}_{2}$ with $\mathrm{k}=0.040 \mathrm{~min}^{-1}$ (Ibukun et al., 2019), g- $\mathrm{C}_{3} \mathrm{~N}_{4} / \mathrm{MnV}_{2} \mathrm{O}_{6}(1: 1), \mathrm{k}=0.022 \mathrm{~min}^{-1}$ (Nithya et al., 2019);

$\mathrm{CaTiO}_{3}: 0.5 \% \mathrm{Eu}^{3+}, \mathrm{k}=0.005 \mathrm{~min}^{-1}$ (Chen et al., 2020b); and $\mathrm{Bi}_{2} \mathrm{CrO}_{6}, \mathrm{k}=0.006 \mathrm{~min}^{-1}$ (Li et al., 2020).

$<$ Insert Fig. 6 here $>$ $<$ Insert Table 3 here $>$ 


\subsubsection{Influence of free radical scavengers on catalyst performance}

Since the photodegradation efficiency of the catalyst is likely to depend on the concentration of free radicals at the surface, free radical scavengers can affect photodegradation performance. Here, in order to examine the factors affecting the performance of the catalyst, isopropanol (IP) as $\bullet \mathrm{OH}$ radical scavenger, pbenzoquinone (BQ) as an $\bullet \mathrm{O}_{2}{ }^{-}$radical scavenger and ammonium oxalate $(\mathrm{AO})$ as $\mathrm{h}^{+}$ scavenger were added to the reaction system (Wen et al., 2016; Chen et al., 2020a). Under illumination from a xenon lamp, the removal efficiencies of $\mathrm{MB}$ with $\mathrm{BQ}, \mathrm{AO}$ and IP were $88.6 \%, 93.9 \%$ and $95.0 \%$, respectively (Fig. 7) compared to a MB removal efficiency of 99.9 with no added scavengers Similarly, the removal efficiencies for CR after adding BQ, AO and IP were 64.9, 83.5 and 88.4\% respectively, compared to $90.8 \%$ without any added scavenger.

The presence of $\mathrm{BQ}$, significantly inhibited the removal efficiencies of both $\mathrm{MB}$ and CR This was because BQ leads a decrease in the amount of superoxide radicals present, which leads to a significant decrease in the photodegradation rate (Table 4). in comparison, AO and IP induced only slight decreases in the removal efficiencies of MB and CR. These experimental results imply the while the formation of $\bullet \mathrm{O}_{2}{ }^{-}$and $\mathrm{h}^{+}$ in the photocatalytic reaction are both essential for a high removal efficiency, $\bullet \mathrm{O}_{2}{ }^{-}$is the dominant reactive species in this reaction.

These observations allow a removal mechanism to be proposed. When the CSC is irradiated by a xenon lamp, $\mathrm{h}^{+}$electron holes are generated in the collision gap. Oxygen molecules in the mixed solution form $\bullet \mathrm{O}_{2}{ }^{-}$superoxide radicals by electron 
removal, and holes $\left(\mathrm{h}^{+}\right)$react with water to form $\bullet \mathrm{OH}$ radical (Baliarsingh et al., 2014).

$$
\begin{aligned}
& <\text { Insert Fig. } 7 \text { here }> \\
& <\text { Insert Table } 4 \text { here }>
\end{aligned}
$$

The addition of hydrogen peroxide $\left(\mathrm{H}_{2} \mathrm{O}_{2}\right)$ is often used as an amendment to enhance photocatalytic degradation of organic materials by enhancing free radical generation. Here, under $\mathrm{H}_{2} \mathrm{O}_{2}$ assisted photocatalysis, the removal efficiencies of $\mathrm{MB}$ and $\mathrm{CR}$ were $99.9 \%$ and $97.1 \%$, respectively, indicating that compared to the blank samples (99.6\% and 90.8\%), the addition of $\mathrm{H}_{2} \mathrm{O}_{2}$ significantly improved the photodegradation removal efficiency. The reaction rate constants of the two dyes were also close to each other, indicating that these two dyes were removed via similar mechanisms.

$\mathrm{H}_{2} \mathrm{O}_{2}$ assisted photocatalysis works through the formation of hydrogen peroxide ion $\left(\mathrm{HO}_{2}^{-}\right)$via reaction with $\mathrm{H}_{2} \mathrm{O}$, accelerating the hydrolysis of $\mathrm{H}_{2} \mathrm{O}_{2}$ forming $\mathrm{OH}$ radical, and is accompanied by the formation of hydrogen hydrate ion $\left(\mathrm{H}_{3} \mathrm{O}^{+}\right)$ (Kausley et al., 2017), and the further reaction of $\mathrm{HO}_{2}{ }^{-}$and $\mathrm{H}_{2} \mathrm{O}_{2}$ forms $\mathrm{OH}$ radical, which is the decisive step of the degradation rate of organic pollutants in aqueous solution (Li et al., 2018). The reaction mechanism is summarized as follows:

$$
\begin{gathered}
\mathrm{H}_{2} \mathrm{O}_{2}+\mathrm{H}_{2} \mathrm{O} \longrightarrow \mathrm{H}_{2} \mathrm{O}^{-}+\mathrm{H}_{3} \mathrm{O}^{+} \\
\mathrm{H}_{2} \mathrm{O}_{2}+\mathrm{HO}_{2}^{-} \longrightarrow \mathrm{OH} \cdot+\mathrm{HO}_{2} \cdot+\mathrm{OH}^{-}
\end{gathered}
$$

In the process of photocatalytic degradation of dyes, the electrons generated by the catalyst can react with $\mathrm{O}_{2}$ to form $\bullet \mathrm{O}_{2}^{-}$, and then the products can react with water 
555

556

557

558

559

560

561

562

563

564

565

566

567

568

569

570

571

572

573

574

575

576

577

to form hydrogenated oxygen radicals $\left(\mathrm{HO}_{2} \bullet\right)$ and hydroxyl radicals $\left(\mathrm{OH}^{-}\right)$. The generated $\mathrm{HO}_{2} \bullet$ rearranges to form oxygen $\left(\mathrm{O}_{2}\right)$ and peroxide hydrogen $\left(\mathrm{H}_{2} \mathrm{O}_{2}\right)$ (Kumar et al., 2015), and $\mathrm{H}_{2} \mathrm{O}_{2}$ reacts with superoxide radical to form hydroxyl radical $\left(\mathrm{OH}^{-}\right)$. The generated hole $\left(\mathrm{h}^{+}\right)$interacts with water to form a highly reactive hydroxyl radical, the hole itself can also attack dye molecules to produce by-products as well. After the formation of free radicals, the reactive substance $\left(\bullet \mathrm{O}_{2}{ }^{-}\right)$attacks dye molecules until the end of decolourisation and ring opening reaction, effectively degrading the dye into smaller intermediates and the final products $\left(\mathrm{CO}_{2}\right.$ and $\left.\mathrm{H}_{2} \mathrm{O}\right)$ (Kaviyarasu et al., 2017; Magdalane et al., 2016; Chen et al., 2008). The possible photocatalytic reactions are as follows:

$$
\begin{aligned}
& \mathrm{CaO}+\mathrm{hv} \longrightarrow \mathrm{h}^{+}+\mathrm{e}^{-} \\
& \mathrm{e}^{-}+\mathrm{O}_{2} \longrightarrow \mathrm{O}_{2}^{-} \\
& \cdot \mathrm{O}_{2}{ }^{-}+\mathrm{H}_{2} \mathrm{O} \longrightarrow \mathrm{OH}^{-}+\mathrm{HO}_{2} \cdot \\
& 2 \mathrm{HO}_{2} \cdot \longrightarrow \mathrm{O}_{2}+\mathrm{H}_{2} \mathrm{O}_{2} \\
& \mathrm{H}_{2} \mathrm{O}_{2}+\cdot \mathrm{O}_{2}^{-} \longrightarrow \mathrm{O}_{2}+\mathrm{OH}^{-}+\cdot \mathrm{OH} \\
& \mathrm{h}^{+}+\mathrm{H}_{2} \mathrm{O} \longrightarrow \mathrm{OH}^{+} \mathrm{H}^{+} \\
& \text {Dye }+\mathrm{hv} \longrightarrow \text { Dye* }^{*}
\end{aligned}
$$

\subsection{Proposed photocatalytic mechanism}

Based on the above experimental studies, a possible mechanism for the photocatalytic degradation of dyes by the CSC produced here was proposed (Fig S3).

Under light irradiation, the electrons gain sufficient energy to become excited and 
transition from the valence band to the conduction band, and form excitons (electronhole pairs). These excitons are known to act in four potential ways: (1) intralattice recombination, (2) recombination at surface active sites, (3) hole $\left(\mathrm{h}^{+}\right)$oxidizes external dyes, and (4) electron ( $\left.\mathrm{e}^{-}\right)$reduces external dyes. High photocatalytic activity can be achieved through the minimum photocatalytic system of electron hole recombination, and the combination of effective absorption and enhanced electron transition from heterojunctions among some dislocations in the crystal structures $\mathrm{Xu}$ et al., 2018; Park et al., 2014). It was previously reported that photocatalytic degradation efficiency can also be further improved via effective size reduction of $\mathrm{CaO}$ nanoparticles and the innate nano properties of the initial raw materials (Anantharaman et al., 2016). Hence, calcium oxide nanoparticles synthesized by calcination of marine biomass, such as shells or other biomass materials containing metal oxides and trace transition metals, which can act as excellent natural photocatalysts for the degradation of dyes from the textile industries. In contrast, while the photodegradation efficiency of $50 \mathrm{mg} \mathrm{CaO}$ derived from eggshell biomass catalyst can reach $96.2 \%$ at an initial MB dye concentration of $20 \mathrm{mg} \mathrm{L}^{-1}$ through parameter optimization (Sree et al, 2020), here, the photodegradation efficiency using a $20 \mathrm{mg}$ CSC derived from marine biomass reached $99.6 \%$ for an initial MB dye solution concentration of $100 \mathrm{mg} \mathrm{L}^{-1}$.

\subsection{Feasibility of practical application}

In the textile industry, dye wastewater typically contains many kinds of different dyes which need to be simultaneously removed. Hence here, the feasibility of 
600

601

applying a CSC for practical wastewater treatment was evaluated in a mixed dye solution. The results indicated that $20 \mathrm{mg}$ of CSC could easily degrade both a mixed dark colored binary dye solution (100 ppm MB + 100 ppm CR) and a ternary dye system $(75$ ppm $\mathrm{MB}+75 \mathrm{ppm} \mathrm{CR}+75 \mathrm{ppm}$ rhodamine $\mathrm{B}(\mathrm{Rh} \mathrm{B}))$ into a transparent solution (Fig S4). Analysis of the absorption spectra of the mixed dye solution system under visible-light irradiation, showed that the initial peaks of the mixed dye solution decreased sharply as reaction time increases, with some peaks shifting slightly or completely disappearing, which strongly suggested that mixtures of dye molecules were destroyed or degraded, and new substances were formed.

\section{Conclusion}

A novel photocatalyst nanomaterial derived from natural clam shell was successfully prepared via a facile calcination process. The as prepared material was then evaluated for its potential to treat dye contaminated wastewater. Under xenon lamp illumination, the overall absorbance- photocatalytic removal efficiencies for 100 $\mathrm{mg} \mathrm{L}^{-1} \mathrm{MB}$ and $500 \mathrm{mg} \mathrm{L}^{-1} \mathrm{CR}$ reached 99.6 and $83.3 \%$, respectively. Increasing the calcination temperature enhanced the catalytic performance of the catalyst. This was attributed to synergetic effects of increased absorption together with increased heterojunctions among some dislocations in the crystal structures. Increased numbers of heterojunction can greatly reduce the energy required for electron transition, making it much easier to form holes and excited electrons. Consequently, the inexpensive clam shell photocatalyst, synthesized in this work from a marine biowaste, may have great potential for future practical large-scale industrial 
wastewater treatment applications.

\section{Declaration of Competing Interest}

The authors declare that they have no known competing financial interests or personal relationships that could have appeared to influence the work reported in this paper.

\section{Acknowledgments}

This work is supported by the National Key Research and Development Projects of China (No. 2020YFE0200100, 2019YFD0900904). We also gratefully acknowledge the funding support from the Fundamental Research Funds for Zhejiang Provincial Universities and Research Institutes (No. 2019J00045) which has made this work possible, as well as the Bureau of Science and Technology of Zhoushan (No: 2018C21020).

\section{References}

1. Aboutaleb, W.A., Elsalamony, R.A., 2019. Effect of $\mathrm{Fe}_{2} \mathrm{O}_{3}-\mathrm{CeO}_{2}$ nanocomposite synthesis method on the Congo red dye photodegradation under visible light irradiation. Mater Chem Phys, 236, 121724

2. Anantharaman, A., Ramalakshmi, S., George, M., 2016. Green Synthesis of Calcium Oxide Nanoparticles and Its Applications. Int J Eng Res Appl. 6, 27-31.

3. Ardejani, F.D., Badii, K., Limaee, N.Y., Shafaei, S.Z., Mirhabibi, A.R., 2008. Adsorption of Direct Red 80 dye from aqueous solution onto almond shells: effect of $\mathrm{pH}$, initial concentration and shell type. J Hazard Mater, 151, 730-737.

4. Asaoka, S., Yamamoto, T., Kondo, S., Hayakawa, S., 2009. Removal of hydrogen sulfide using crushed oyster shell from pore water to remediate 
organically enriched coastal marine sediments, Bioresource Technol. 100, 41274132.

5. Balakrishnan, V.K., Shirin, S., Aman, A., Solla, S.R., Mathieudenoncourt, J., Langlois, V. S., 2016. Genotoxic and carcinogenic products arising from reductive transformations of the azo dye, Disperse Yellow 7. Chemosphere, 146, 206-215.

6. Baliarsingh, N., Parida, K.M., Pradhan, G.C., 2014. Effects of Co, Ni, Cu, and Zn on Photophysical and Photocatalytic Properties of Carbonate Intercalated MII/Cr LDHs for Enhanced Photodegradation of Methyl Orange. Ind Eng Chem Res, 53, 3834-3841.

7. Chen, J., Luo, W., Yu, S., Yang, X., Wu, Z., Zhang, H., Gao, J., Mai, Y., Li, Y., Jia, Y., 2020a. Synergistic effect of photocatalysis and pyrocatalysis of pyroelectric $\mathrm{ZnSnO}_{3}$ nanoparticles for dye degradation. Ceram Int, 46, 97869793.

8. Chen, J., Sheng, Y., Song, Y., Chang, M., Zhang, X., Cui, L., Meng, D., Zhu, H., Shi, Z., Zou, H., 2018. Multimorphology mesoporous silica nanoparticles for dye adsorption and multicolor luminescence applications. ACS Sustain Chem Eng, 6, 3533-3545.

9. Chen, M., Xiong, Q., Liu, Z., Qiu, K., Xiao, X., 2020b. Synthesis and photocatalytic activity of $\mathrm{Na}^{+}$co-doped $\mathrm{CaTiO}_{3}: \mathrm{Eu}^{3+}$ photocatalysts for methylene blue degradation. Ceram Int, 46, 12111-12119.

10. Chen, T., Zheng, Y., Lin, J. M., Chen, G., 2008. Study on the photocatalyticdegradation of methyl orange in water using $\mathrm{Ag} / \mathrm{ZnO}$ as catalyst by 
liquid chromatography electrospray ionization ion-trap mass spectrometry. J Am Soc Mass Spectr, 19, 997-1003.

11. Chequer, F.M., Angeli, J.P., Ferraz, E.R., Tsuboy, M.S., Marcarini, J.C., Mantovani, M.S., Oliveira, D.P., 2009. The azo dyes Disperse Red 1 and Disperse Orange 1 increase the micronuclei frequencies in human lymphocytes and in HepG2 cells. Mutat Res-Gen Tox En, 676 (1), 83-86.

12. Dai, L., Zhu, W., He, L., Tan, F., Zhu, N., Zhou, Q., He, M., Hu, G., 2018. Calcium-rich biochar from crab shell: An unexpected super adsorbent for dye removal. Bioresource Technol, 267, 510-516.

13. Hosseinzadeh, H., Mohammadi, S., 2015. Quince seed mucilage magnetic nanocomposites as novel bioadsorbents for efficient removal of cationic dyes from aqueous solutions. Carbohyd Polym, 134, 213-221.

14. Ibukun, O., Evans, P.E., Dowben, P.A., Jeong, H.K., 2019. Titanium dioxidemolybdenum disulfide for photocatalytic degradation of methylene blue. Chem Phys, 525, 110419.

15. Ismail, M., Wu, Z., Zhang, L., Ma, J., Jia, Y., Hu, Y., Wang, Y., 2019. Highefficient synergy of piezocatalysis and photocatalysis in bismuth oxychloride nanomaterial for dye decomposition. Chemosphere, 228, 212-218.

16. Jiang, D., Cai, L., Ji, L., Zhang, H., Song, W., 2018. Nano-Bi2MoO6/calcined mussel shell composites with enhanced photocatalytic performance under visiblelight irradiation. Micro Nano Lett, 13, 1021-1025.

17. Jung, J., Yoo, K., Kim, H. G., Lee, H.K., Shon, B., 2007. Reuse of Waste Oyster Shells as a $\mathrm{SO}_{2} / \mathrm{NO}_{\mathrm{x}}$ Removal Absorbent. J Ind and Eng Chem, 13, 512-517. 
18. Kausley, S., Desai, K.S., Shrivastava, S., Shah, P.R., Patil, B.R., Pandit, A.B., 2017. Mineralization of alkyd resin wastewater: Feasibility of different advanced oxidation processes. J Environ Chem Eng, 6, 3690-3701.

19. Kaviyarasu, K., Kotsedi, L., Simo, A., Fuku, X., Mole, G. T., Kennedy, J., Maaza, M., 2017. Photocatalytic activity of $\mathrm{ZrO}_{2}$ doped lead dioxide nanocomposites: Investigation of structural and optical microscopy of RhB organic dye. Appl Surf Sci, 421, 234-239.

20. Kumar, R., Umar, A., Kumar, G., Akhtar, M.S., Wang, Y., Kim, S.H., 2015. Cedoped $\mathrm{ZnO}$ nanoparticles for efficient photocatalytic degradation of direct red-23 dye. Ceram Int, 41, 7773-7782.

21. Li, Y., Li, L., Chen, Z., Zhang, J., Gong, L., Wang, Y., Zhao, H., Mu, Y., 2018. Carbonate-activated hydrogen peroxide oxidation process for azo dye decolorization: Process, kinetics, and mechanisms. Chemosphere, 192, 372-378.

22. Li, Z., Zhang, Z., Wang, L., Meng, X., 2020. Bismuth chromate $\left(\mathrm{Bi}_{2} \mathrm{CrO}_{6}\right)$ : A promising semiconductor in photocatalysis. J Catal, 382, 40-48.

23. Liu, R., Liu, Y., Zhu, X., Zhang, Z., Zhang, J., Dang, F., 2014. Biomass-derived highly porous functional carbon fabricated by using a free-standing template for efficient removal of methylene blue. Bioresource Technol, 154, 138-147.

24. Ma, C., Wang, F., Zhang, C., Yu, Z., Wei, J., Yang, Z., Li, Y., Li, Z., Zhu, M., Shen, L., Zeng, G., 2017. Photocatalytic decomposition of Congo red under visible light irradiation using $\mathrm{MgZnCr}^{-} \mathrm{TiO}_{2}$ layered double hydroxide. Chemosphere, 168, 80-90. 
25. Magdalane, C.M., Kaviyarasu, K., Vijaya, J.J., Siddhardha, B., Jeyaraj, B., 2016. Photocatalytic activity of binary metal oxide nanocomposites of $\mathrm{CeO}_{2} / \mathrm{CdO}$ nanospheres: Investigation of optical and antimicrobial activity. J Photoch Photobio B, 163, 77-86.

26. Nautiyal, P., Subramanian, K.A., Dastidar, M.G., 2016. Adsorptive removal of dye using biochar derived from residual algae after in-situ transesterification: Alternate use of waste of biodiesel industry. J Environ. Manage, 182, 187-197.

27. Nguyen, C. H., Fu, C., Juang, R., 2018. Degradation of methylene blue and methyl orange by palladium-doped $\mathrm{TiO}_{2}$ photocatalysis for water reuse: Efficiency and degradation pathways. J Clean Prod, 202, 413-427.

28. Nithya, M., Vidhya, S., Keerthi., 2019. A Novel g- $\mathrm{C}_{3} \mathrm{~N}_{4} / \mathrm{MnV}_{2} \mathrm{O}_{6}$ Heterojunction Photocatalyst for the Removal of Methylene Blue and Indigo Carmine. Chem Phys Lett, 737, 136832.

29. Park, S., Lee, C.W., Kang, M.G., Kim, S., Kim, J.H., Kwon, J.E., Park, S.Y., Kang, C., Hong, K.S., Nam, K., 2014. A ferroelectric photocatalyst for enhancing hydrogen evolution: polarized particulate suspension. Phys Chem Chem Phys, 16, 10408-10413.

30. Park, W. H., Polprasert, C., 2008. Roles of oyster shells in an integrated constructed wetland system designed for P removal. Ecol Eng, 34, 50-56.

31. Parvin, S., Biswas, B.K., Rahman, A., Rahman, H., Anik, S., Uddin, R., 2019. Study on adsorption of Congo red onto chemically modified egg shell membrane. Chemosphere, 236, 124326. 
32. Penarodriguez, S., Fernandezcalvino, D., Novoamunoz, J.C., Ariasestevez, M., Nunezdelgado, A., Fernandezsanjurjo, M.J., Alvarezrodriguez, E., 2010. Kinetics of $\mathrm{Hg}(\mathrm{II})$ adsorption and desorption in calcined mussel shells. J Hazard Mater, $180,622-627$.

33. Peralta, M.D., Sanchezcantu, M., Puentelopez, E., Rubiorosas, E., Tzompantzi, F., 2017. Evaluation of calcium oxide in Rhodamine 6G photodegradation. Catal Today, 305, 75-81.

34. Secoreigosa, N., Cutillasbarreiro, L., Novoamunoz, J. C., Ariasestevez, M., Fernandezsanjurjo, M. J., Alvarezrodriguez, E., Nunezdelgado, A., 2014. Mixtures including wastes from the mussel shell processing industry: retention of arsenic, chromium and mercury. J Clean Prod, 84, 680-690.

35. Shajahan, S., Arumugam, P., Rajendran, R., Munusamy, A.P., 2020. Optimization and detailed stability study on $\mathrm{Pb}$ doped ceria nanocubes for enhanced photodegradation of several anionic and cationic organic pollutants. Arab J Chem, 13, 1309-1322.

36. Shariffuddin, J.H., Yean, W.C., Ghazali, S.S., 2018. Investigating the catalytic properties of calcium compounds derived from marine based shell waste for wastewater treatment, Materials Today Proceed. 5, 21718-21727.

37. Sree, G.V., Nagaraaj, P., Kalanidhi, K., Aswathy, C.A., Rajasekaran, P., 2020. Calcium oxide a sustainable photocatalyst derived from eggshell for efficient photodegradation of organic pollutants, J Clean Prod. 270, 122294-122302. 
38. Tangboriboon, N., Kunanuruksapong, R., Sirivat, A., 2012. Preparation and properties of calcium oxide from eggshells via calcination. Mater Sci-poland, 30, $313-322$

39. Tsai, C., Tseng, W.J., 2020. Preparation of $\mathrm{TiN}_{-} \mathrm{TiO}_{2}$ composite nanoparticles for organic dye adsorption and photocatalysis. Ceram Int, 46, 14529-14535.

40. Wei, D., Zhang, H., Cai, L., Guo, J., Wang, Y., Ji, L., Song, W., 2018. Calcined Mussel Shell Powder (CMSP) via Modification with Surfactants: Application for Antistatic Oil-Removal. Materials, 11, 1410.

41. Wen, X., Zhang, C., Niu, C., Zhang, L., Huang, D., Wang, X., Zhang, X., Zeng, G., 2016. Facile synthesis of a visible light $\alpha$-Fe2O3/BiOBr composite with high photocatalytic performance. RSC Adv, 6, 4035-4042.

42. Xu, X., Wu, Z., Xiao, L., Jia, Y., Ma, J., Wang, F., Wang, L., Wang, M., Huang, H., 2018. Strong piezo-electro-chemical effect of piezoelectric BaTiO3 nanofibers for vibration-catalysis. J Alloy Compd, 762, 915-921.

43. Yao, X., Ji, L., Guo, J., Ge, S., Lu, W., Cai, L., Wang, Y., Song, W., Zhang, H., 2020. Magnetic activated biochar nanocomposites derived from wakame and its application in methylene blue adsorption. Bioresource Technol, 302, 122842.

44. Zhou, Y., Zhang, H., Cai, L., Guo, J., Wang, Y., Ji, L., Song, W., 2018. Preparation and characterization of macroalgae biochar nanomaterials with highly efficient adsorption and photodegradation Ability. Materials, 11, 1709-1718.

45. Zhu, C., Wang, L., Kong, L., Yang, X., Wang, L., Zheng, S., Chen, F., Maizhi, F., Zong, H., 2000. Photocatalytic degradation of AZO dyes by supported TiO2 + UV in aqueous solution. Chemosphere, 41, 303-309. 


\section{Figure captions:}

784 Figure 1. SEM images of clam shell samples: (a), (b) uncalcined; (c), (d) treated at $800{ }^{\circ} \mathrm{C}$; (e), (f) treated at $900{ }^{\circ} \mathrm{C} ;(\mathrm{g}),(\mathrm{h})$ treated at $1000{ }^{\circ} \mathrm{C}$; and TEM image (i), (j) and (k) treated at $1000{ }^{\circ} \mathrm{C}$.

Figure 2. (a) XRD spectra of uncalcined, treated at 800,900 , and $1000{ }^{\circ} \mathrm{C}$ clam shell samples. (b) Thermogravimetric analysis of clam shell during calcination process. (c) Absorption spectrum and (d) optical band gap of different clam shell samples.

789

790

791

792

793

794

795

796

797

798

799

800

801

802
Figure 3. (a) XPS survey scan of CSCs at $800^{\circ} \mathrm{C}$ and $1000^{\circ} \mathrm{C}$; XPS spectra of clam shell samples at: $800{ }^{\circ} \mathrm{C}$ (b) $\mathrm{Ca} 2 \mathrm{p}$, (c) $\mathrm{C} 1 \mathrm{~s}$, (d) $\mathrm{O} 1 \mathrm{~s}$, and $1000^{\circ} \mathrm{C}$ (e) Ca2p, (f) C1s, (g) O1s of CSCs.

Figure 4. Photocatalytic experiments of $\operatorname{MB}(a, b$,$) and C R(c, d$, ) with calcined catalysts at different temperatures: (a), (c) curve of removal rate with time, (b), (d) plot of log of concentration with time. Photodegradation absorption spectra of (e) MB and (f) CR solutions in the presence of clam shell powder calcined at $1000^{\circ} \mathrm{C}$.

Figure 5. Photocatalytic experiment of $\mathrm{MB}(\mathrm{a}, \mathrm{b}, \mathrm{c})$ and $\mathrm{CR}(\mathrm{d}, \mathrm{e}, \mathrm{f})$ with different doses of clam shell at $1000{ }^{\circ} \mathrm{C}$ ((a), (d) curve of absorbance with time, (b), (e) curve of removal rate with time, (c), (f) plot of $\log$ of concentration with time.

Figure 6. Photocatalytic experiment of clam shell at $100{ }^{\circ} \mathrm{C}$ for $\mathrm{MB}$ (a, b, c) and CR (d, e, f); Curves of absorbance with time (a) and (d); Curves of removal rate with time (b), (e); Plots of log of concentration with time (c), (f).

Figure 7. Effects of scavenger and superoxide on MB (a, b, c) and CR (d, e, f) degradation. 

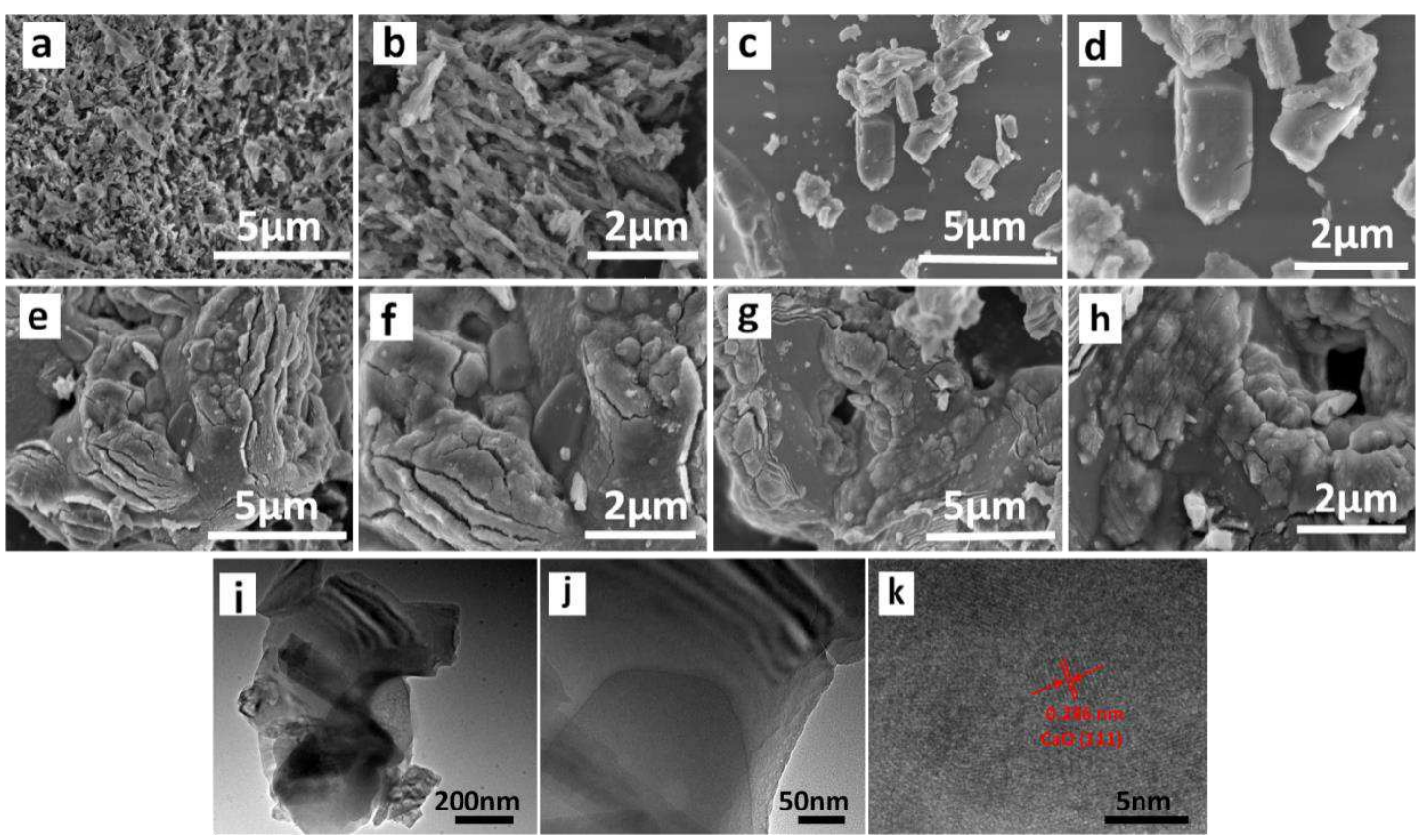

k

Figure 1. SEM images of clam shell samples: (a), (b) uncalcined; (c), (d) treated at $800{ }^{\circ} \mathrm{C}$; (e), (f) treated 

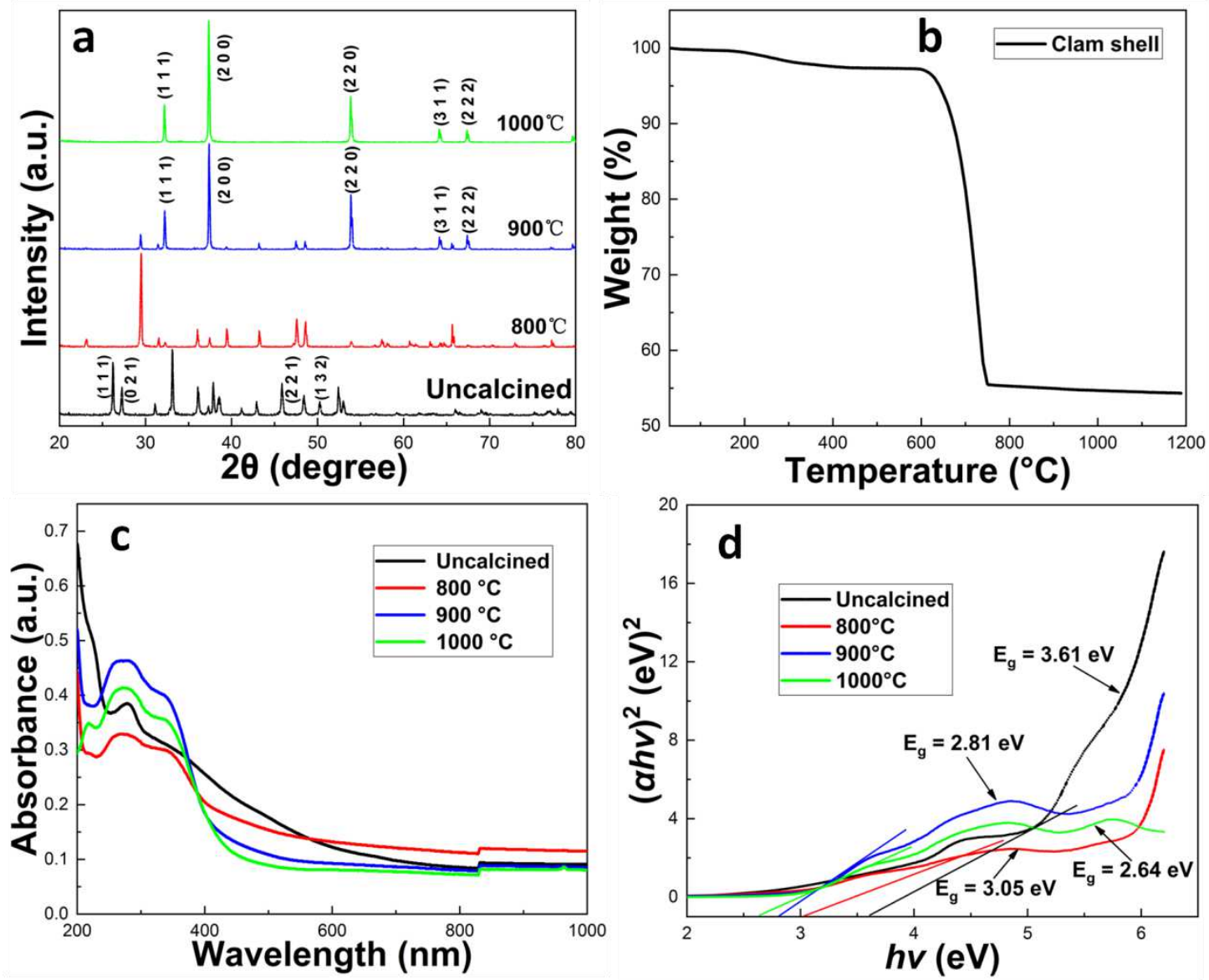

810

Thermogravimetric analysis of clam shell during calcination process. (c) Absorption spectrum and (d) optical band gap of different clam shell samples. 

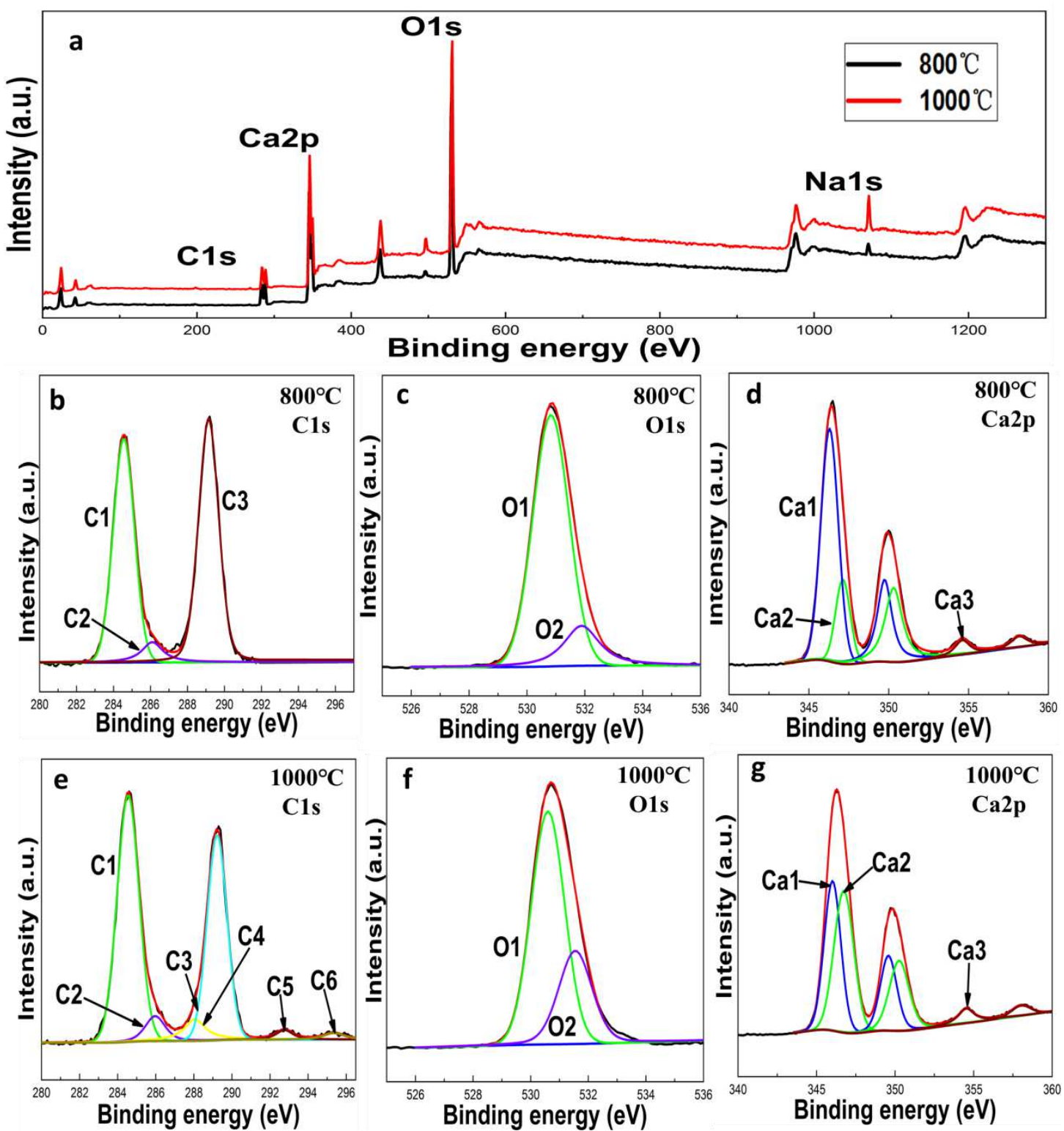

825

Figure 3. (a) XPS survey scan of CSCs at $800^{\circ} \mathrm{C}$ and $1000^{\circ} \mathrm{C}$; XPS spectra of clam shell samples at: $800{ }^{\circ} \mathrm{C}$ (b) $\mathrm{Ca} 2 \mathrm{p}$, (c) C1s, (d) $\mathrm{O} 1 \mathrm{~s}$, and $1000^{\circ} \mathrm{C}$ (e) Ca2p, (f) $\mathrm{C} 1 \mathrm{~s}$, (g) O1s of CSCs. 

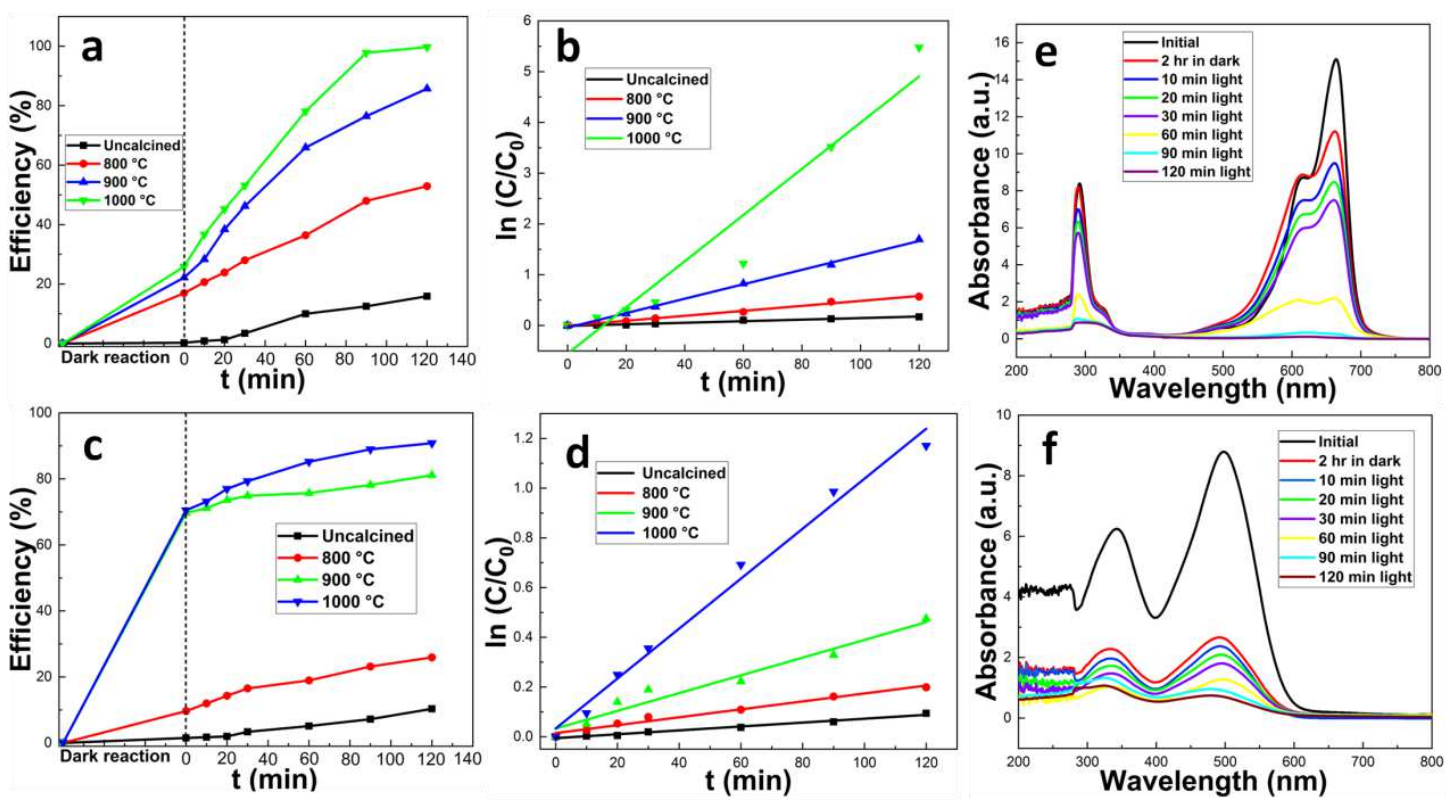

835

Figure 4. Photocatalytic experiments of $\mathrm{MB}(\mathrm{a}, \mathrm{b}$,$) and \mathrm{CR}(\mathrm{c}, \mathrm{d}$,) with calcined catalysts at different temperatures: (a), (c) curve of removal rate with time, (b), (d) plot of log of concentration with time. Photodegradation absorption spectra of (e) MB and (f) CR solutions in the presence of clam shell powder calcined at $1000^{\circ} \mathrm{C}$. 

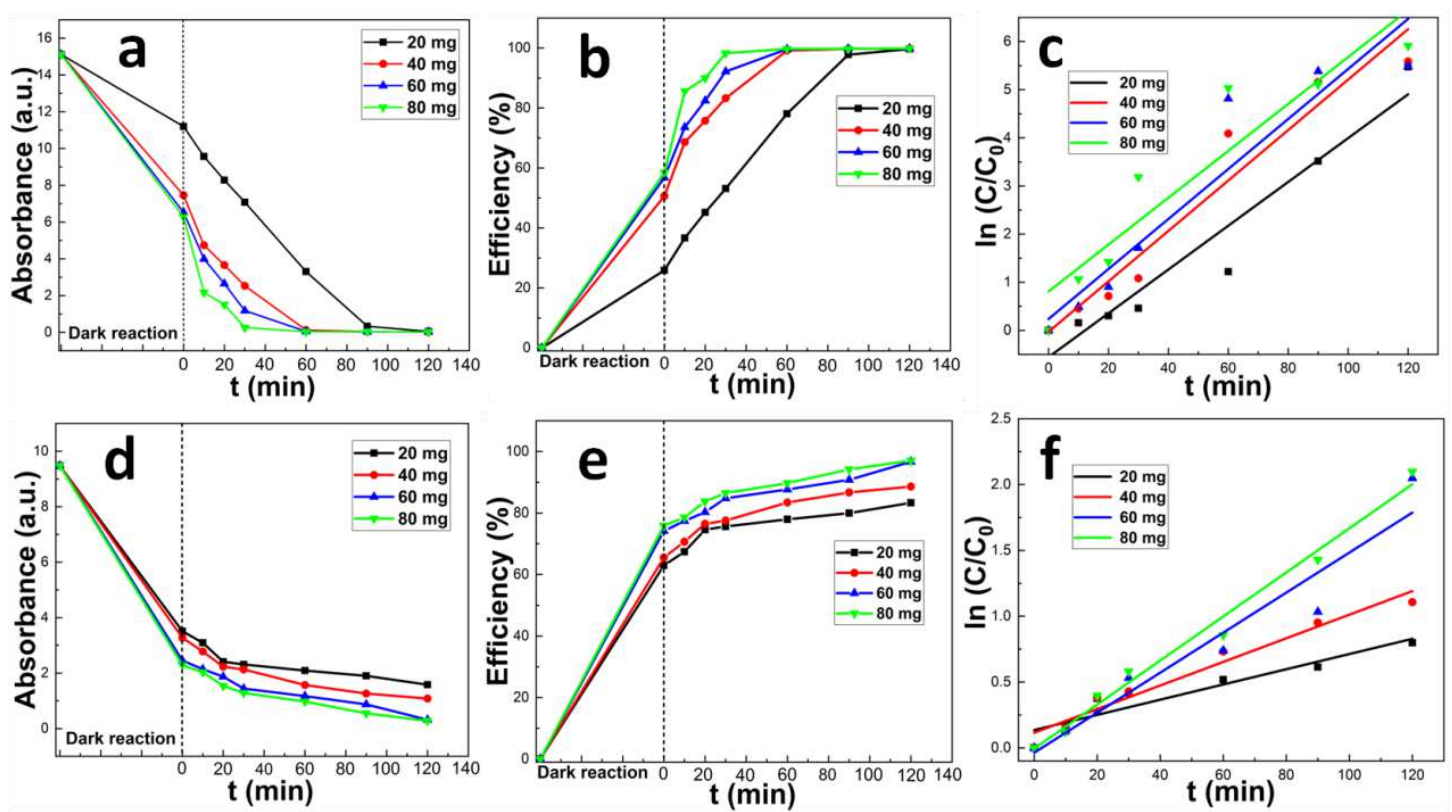

Figure 5. Photocatalytic experiment of $\mathrm{MB}(\mathrm{a}, \mathrm{b}, \mathrm{c})$ and $\mathrm{CR}(\mathrm{d}, \mathrm{e}, \mathrm{f})$ with different doses of clam shell at

$8531000{ }^{\circ} \mathrm{C}((\mathrm{a}),(\mathrm{d})$ curve of absorbance with time, (b), (e) curve of removal rate with time, (c), (f) plot of $854 \log$ of concentration with time.

855

856

857

858

859

860

861

862 
867

868

869

870

871

872

873

874

875

876

877

878

879

880

881 876
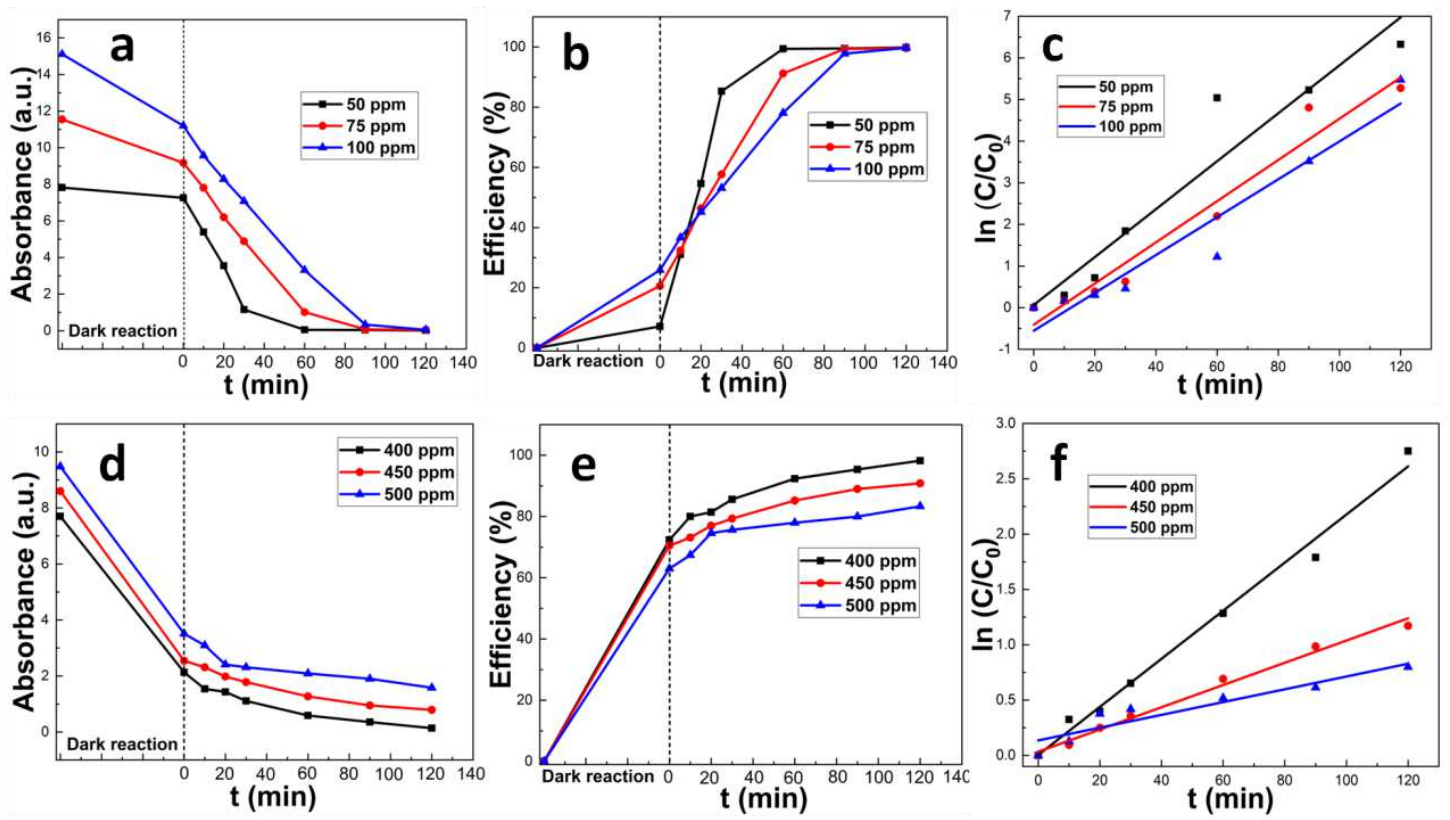

Figure 6. Photocatalytic experiment of clam shell at $1000^{\circ} \mathrm{C}$ for $\mathrm{MB}(\mathrm{a}, \mathrm{b}, \mathrm{c})$ and $\mathrm{CR}(\mathrm{d}, \mathrm{e}, \mathrm{f})$; Curves of absorbance with time (a) and (d); Curves of removal rate with time (b), (e); Plots of log of concentration with time (c), (f).

(

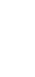

in

75 

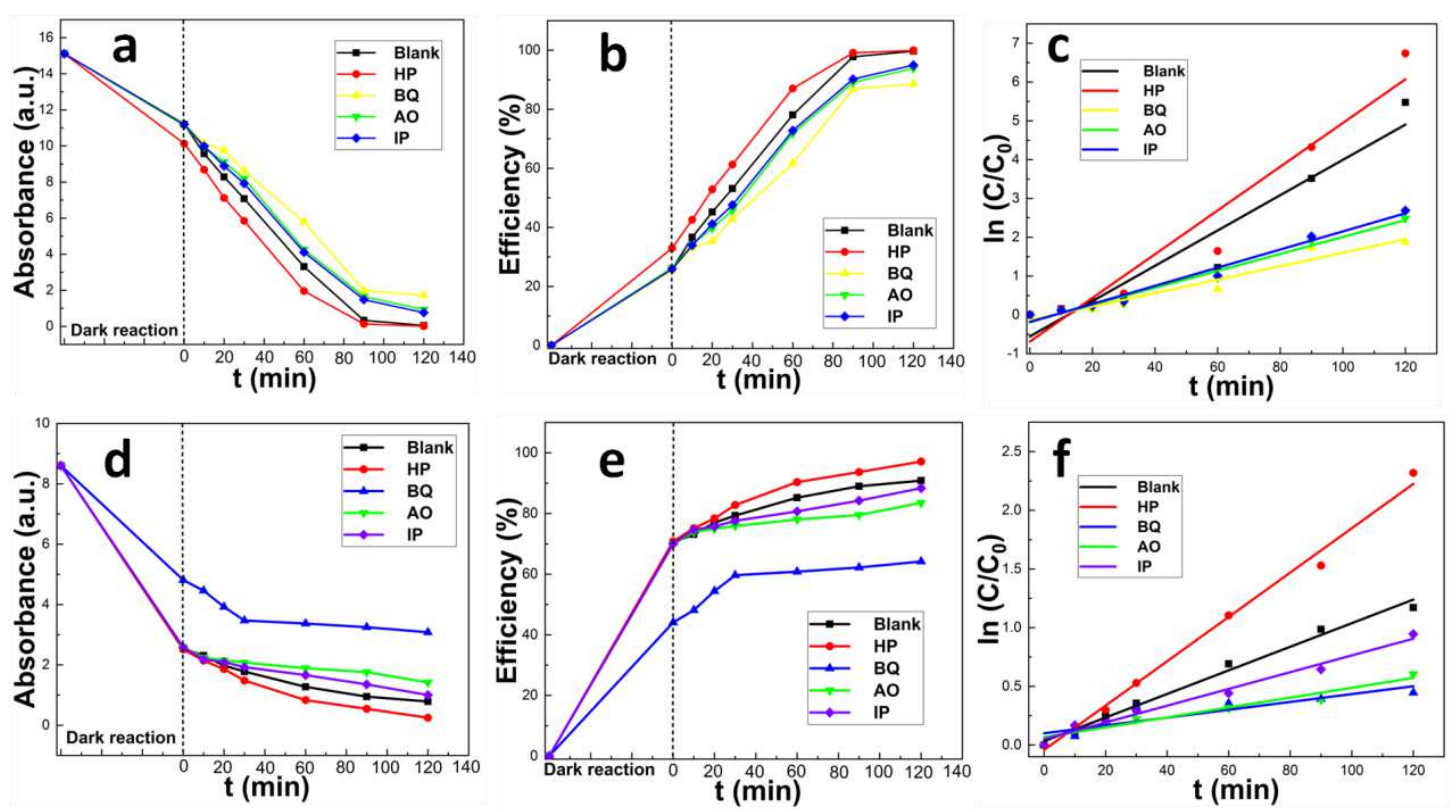

884

Figure 7. Effects of scavenger and superoxide on MB (a, b, c) and CR (d, e, f) degradation.

885

886

887

888

889

890

891

892

893

894

895

896 
899 Table 1. Best fit photodegradation kinetic parameters for MB and CR with the four clam shells studied.

\begin{tabular}{cccccc}
\hline Dye & Sample & Uncalcined & $800{ }^{\circ} \mathrm{C}$ & $900{ }^{\circ} \mathrm{C}$ & $1000{ }^{\circ} \mathrm{C}$ \\
\hline $\mathrm{MB}$ & $\mathrm{R}^{2}$ & 0.9733 & 0.9926 & 0.9973 & 0.9211 \\
& $\mathrm{k}$ & 0.0015 & 0.0049 & 0.0142 & 0.0455 \\
$\mathrm{CR}$ & $\mathrm{R}^{2}$ & 0.9779 & 0.9762 & 0.9509 & 0.9869 \\
& $\mathrm{k}$ & 0.0008 & 0.0016 & 0.0036 & 0.0101 \\
\hline
\end{tabular}

900

901

902

903

904

905

906

907

908

Table 2. Variation in best fit degradation kinetic parameters for MB and CR with the CSC dose.

\begin{tabular}{cccccc}
\hline Dye & Catalyst concentration & $20 \mathrm{mg}$ & $40 \mathrm{mg}$ & $60 \mathrm{mg}$ & $80 \mathrm{mg}$ \\
\hline $\mathrm{MB}$ & $\mathrm{R}^{2}$ & 0.9211 & 0.9332 & 0.8797 & 0.8541 \\
& $\mathrm{k}$ & 0.0455 & 0.0524 & 0.0519 & 0.0487 \\
$\mathrm{CR}$ & $\mathrm{R}^{2}$ & 0.9562 & 0.9531 & 0.9228 & 0.9839 \\
& $\mathrm{k}$ & 0.0058 & 0.0090 & 0.0152 & 0.0167 \\
\hline
\end{tabular}

909

910

911

912

913

914 
Table 3. Variation in best fit degradation kinetics parameters for MB and CR with initial dye concentration.

\begin{tabular}{ccccc}
\hline Dye & Dye concentration & $50 \mathrm{ppm}$ & $75 \mathrm{ppm}$ & $100 \mathrm{ppm}$ \\
\hline $\mathrm{MB}$ & $\mathrm{R}^{2}$ & 0.912 & 0.953 & 0.921 \\
& $\mathrm{k}$ & 0.058 & 0.049 & 0.045 \\
\hline \multirow{3}{*}{$\mathrm{CR}$} & Dye concentration & $400 \mathrm{ppm}$ & $450 \mathrm{ppm}$ & $500 \mathrm{ppm}$ \\
& $\mathrm{R}^{2}$ & 0.987 & 0.986 & 0.856 \\
& $\mathrm{k}$ & 0.022 & 0.010 & 0.006 \\
\hline
\end{tabular}

Table 4. Variation in best fit degradation kinetic parameters of $\mathrm{MB}$ and $\mathrm{CR}$ in the presence different scavengers and superoxide.

\begin{tabular}{ccccccc}
\hline Dye & Reagent & Blank & HP & BQ & AO & IP \\
\hline MB & $\mathrm{R}^{2}$ & 0.921 & 0.931 & 0.937 & 0.976 & 0.976 \\
& $\mathrm{k}$ & 0.045 & 0.056 & 0.017 & 0.022 & 0.023 \\
$\mathrm{CR}$ & $\mathrm{R}^{2}$ & 0.986 & 0.991 & 0.884 & 0.933 & 0.978 \\
& $\mathrm{k}$ & 0.010 & 0.019 & 0.003 & 0.004 & 0.007 \\
\hline
\end{tabular}




\section{Supplementary Files}

This is a list of supplementary files associated with this preprint. Click to download.

- SupplementaryMaterials.docx 